\title{
Spectacle Cord-retained Oculo-Orbital Prosthesis
}

\author{
Shefali Goel, Saumyendra V. Singh, Neetu Singh, Deeksha Arya and Pooran Chand \\ Department of Prosthodontics, King George's Medical University, Lucknow, India
}

\begin{abstract}
Retention of an orbital prosthesis plays a key role in treatment success and patient acceptance as does aesthetics. Though numerous retentive aids are available such as implants, adhesives, etc, the cost, surgical aspect, difficulty of use and allergic potential may compromise efficiency. This report describes the case of an 11-year post-enucleation poor retinoblastoma patient, in whom an unfavourable defect leads to a major prosthetic challenge (from point of view of retention and camouflage). This report describes a simple, economical, and user-friendly approach to obtain satisfactory retention and camouflage for such patients with spectacle cords and customised spectacles.
\end{abstract}

Key Words: Oculo-orbital prosthesis, Spectacle, Cord.

How to cite this article: Goel S, Singh SV, Singh N, Arya D, Chand P. Spectacle Cord-retained Oculo-Orbital Prosthesis. J Coll Physicians Surg Pak 2021; 31(05):591-593.

\section{INTRODUCTION}

A facial defect compromises an individual's life by introduction of elements like facial disfigurement, social stigma, psychological strain, and economical predicament. Hence, successful rehabilitation plays an integral role in acclimatisation of patient to a more normal life. An inconspicuous prosthesis plays a major role in restoring aesthetics; and equally significant is the achievement of retention. Inadequate retention is associated with patient distress, prosthesis neglect, and discardment. Multiple methods have been described in literature to achieve adequate retention for orbital prosthesis including use of adhesives, magnets, stud attachments, and implants. ${ }^{1-6}$ While some methods have expense as a limitation; for others, surgical intervention is the majorpitfall.

In childhood, retinoblastoma is one of the most frequently encountered tumors. ${ }^{7}$ It is managed predominantly with the help of enucleation and adjunctive radiotherapy and chemotherapy. Enucleation creates a volume deficit, which is managed with the placementofboth implantand prosthesis. ${ }^{8}$ Failure of early prosthesis wear can contribute to development of socket contracture, which constitutes an integral component of the post-enucleation socket syndrome (PESS). ${ }^{9}$ Management of socket contracture depends on severity of the condition including techniques like anterior lamellar repositioning, mucous membrane grafting, and free vascularised radial forearm flap..$^{9,10}$

Correspondence to: Dr. Saumyendra Vikram Singh, Department of Prosthodontics, King George's Medical University, Lucknow, India

E-mail: saumyendravsingh@rediffmail.com

Received: August 21, 2019; Revised: December 09, 2019; Accepted: December 09, 2019

DOI: https://doi.org/10.29271/jcpsp.2021.05.591

\section{CASE REPORT}

An 11-year male patient reported to the Department of Prosthodontics with the chief complaint of unaesthestic facial appearance, due to loss of left eye. He had been diagnosed with retinoblastoma of left eye about two years back, which was managed by enucleation surgery and chemotherapy. At post-surgery, as a result of not wearing an ocular prosthesis/conformer, patient developed PESS and presented with fused upper and lower eyelids for prosthesis fabrication. He was referred to the Department of Plastic Surgery for creation of a favourably sized defect for prosthesis retention and aesthetics. Unfortunately, the surgeon removed both upper and lower eyelids, and covered the socket defect with a split thickness graft, leading to a large unaesthetic non-retentive defect (Figure 1a). For the lack of existing terminology, the prosthesis thus fabricated, and has been termed an oculo-orbital prosthesis.

A conventional impression of the defect and surrounding tissues was made with irreversible hydrocolloid impression material (Zelgan; Dentsply Pvt.Ltd.) and poured in type IV stone (Kalstone; Kalabhai). This was followed by adaptation of a $2 \mathrm{~mm}$ thick PVC thermoplastic sheet (Sof-tray sheets; Ultradent Products Inc) on the model to facilitate process of pattern trial by enhancing adaptability. A stock ocular prosthesis matching to the contralateral eye in terms of colour, shape and size of sclera and iris, was selected. Its position was adjusted anteroposteriorly, mediolaterally, and superioinferiorly with respect to normal gaze of the contralateral eye. Pattern was fabricated in clay and sculpted in accordance to the normal contralateral eye with subsequent modifications to obtain desired life-like contour and skin texturing by creating skin folds and stippling.

This was followed by thinning and merging of the margins with adjacenttissues. 
Investing of the pattern was done with addition of acrylic stump (Pyrax; Pyrax Polymers Ltd.) on the iris to avoid displacement of the ocular component of the orbital prosthesis, as displacement often leads to altered gaze of the prosthetic eye after processing. Dewaxing procedure was carried out at $100^{\circ} \mathrm{C}$ for 5 minutes. A digital spectrophotometer (e-skin; Spectromatch Ltd.) was utilised for shade matching. Colour-matched Room Temperature Vulcanising (RTV) medical-graded silicone material (Technovent M511; Technovent Ltd) was packed in the investment mould. Post-polymerisation, the prosthesis was deflasked, retrieved, and finished. Extrinsic staining was done for correction of any deficiencies and natural hair were stitched over upper and lower eyelids of the silicone prosthesis using 23 gauge syringe needle.

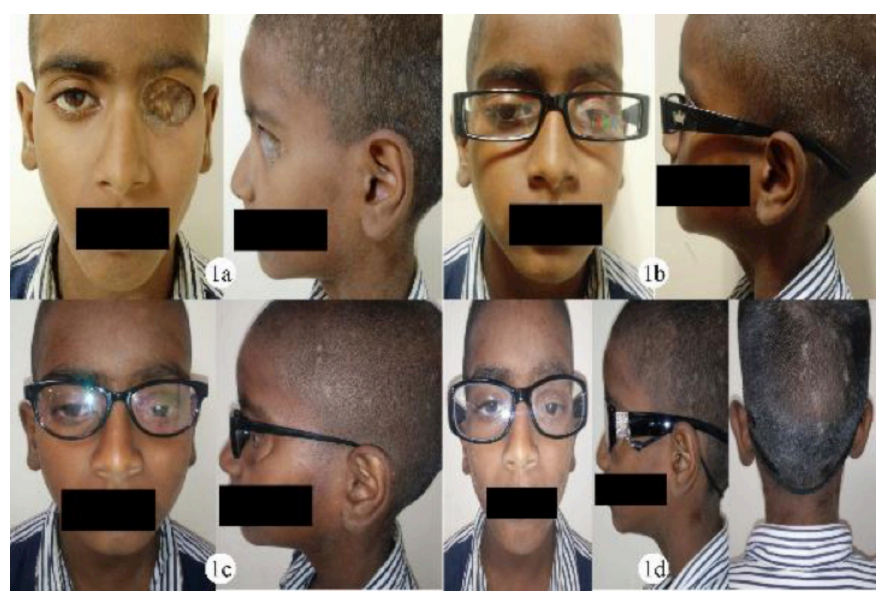

Figure 1: (a) Pre-rehabilitation frontal and profile views. (b) Mismatched spectacle 1 frontal and profile views. (c) Mismatched spectacle 2 frontal and profile views. (d) Matched spectacle with cord and prosthesis in situ: frontal, profile and back views.

To obtain optimum camouflage and retention, customised spectacles with elastic black nylon spectacle cord were utilised (Cord diameter was $0.3 \mathrm{~cm}$ and length $58.5 \mathrm{~cm}$ ). The cord was fastened in proportion to the pressure needed to obtain a stable retentive comfortable prosthesis. For camouflage of the defect prosthesis margins (unfavourable surgical outcome left little place for their concealment), spectacles were used for the patient with wide rimmed frames. The importance of spectacle design in camouflage can be appreciated from Figures la through $1 \mathrm{~d}$. While spectacles in Figure $1 \mathrm{~b}$ lead to lateral margin show through, the ones in Figure $1 \mathrm{c}$ revealed superior margin of the prosthesis. Spectacles in Figure 1d concealed the margins from allaspects. The spectacle shape was chosen to coincide with prosthesis shape, with its bridge as close as possible to the nose. The spectacle temple was chosen to be wide enough to create camouflage in lateral view. Photochromatic lenses were used for obscuring the prosthesis in daylight (Figure 1d).

Prosthesis was delivered to the patient. At the subsequent follow-up visits (now 1 year), patient and guardian expressed satisfaction with improved aesthetics, adequate retention and ease of wear.

\section{DISCUSSION}

Inter-displinary communication plays a major role in successful prosthesis rehabilitation. Proper case planning with involve- ment of both the surgeon and prosthodontist is needed. Clear communication and understanding of factors, such as creation/preservation of undercuts for prosthesis retention, partial/split thickness flap coverage of denuded areas, minimum size and shape of defect necessary for satisfactory prosthetic rehabilitation and/or need of extra retentive mechanisms such as implant placement, is essential. Selection of mode of retention of a prosthesis is dependent on a multitude of factors like defect size and undercut presence, patient's economic status, and aesthetic prominence of the site. Retention for an orbital prosthesis can be obtained through inclusion of anatomical undercuts with conformer/acrylic resin template relined by a resilient denture liner, spectacle retained prosthesis, use of stud attachment, magnets, adhesives and implants. ${ }^{1-6}$

In this patient, no functional undercuts were present, which could be utilised to obtain retention. Since the patient was from poor economic strata and had already undergone debilitating surgeries, implants were not a feasible option. Literature has delineated increased incidences of soft tissue infections and higher hygiene maintenance requirements with implant placement. $^{5,6}$

Adhesive serves as an expensive alternative, which require frequent applications and good manual dexterity on the part of the patient, which becomes more problematic in a paediatric patient. Routine adhesive usage is conducive to allergic responses and may simultaneously also impair prosthesis external pigmentation. ${ }^{3,4}$

In conventional spectacle retained prosthesis, an acrylic shim is utilised to obtain anchorage from the spectacle due to absence of direct bond of silicone with it. ${ }^{9}$ This can hamper the aesthetics due to increased visibility of acrylic shim. In addition, it can introduce an element of difficulty in prosthesis insertion and removal, due to varying path of insertion of the prosthesis and spectacle. Further, the shim takes up additional space, which the concerned defect could not accommodate. Above difficulties can be ameliorated by the use of magnets or studs in the spectacle. ${ }^{3,4}$ However, due to limited depth of this defect and cost, these were not feasible options. In addition, magnets exhibit loss of attraction over time and corrosion. ${ }^{3}$

In this report, positive pressure created by the spectacle and elastic cord, was used for prosthesis retention. Eye-wear cords are nylon extensions with adjustable plastic loops at their end. They are readily available and are an economical retentive aid, affordable even by impoverished patients. The aesthetics of the prosthesis is not compromised by black cords, being camouflaged within scalp hair. They do not demand great manual dexterity from the patient and, therefore, can be used by the very young or old. They can be removed at any desired time and there is negligible likelihood of any allergic reaction.

Aesthetics and retention are two fundamental elements for a successful facial prosthesis, which needs good team-work between the surgeon and prosthodontist. Surgically created 
unfavourable defects such as the one presented, pose a major prosthodontics challenge. This report describes the fabrication of an oculo-orbital prosthesis with spectacle and cord aided camouflage as well as retention, to meet this challenge in an economical and patient-friendly manner.

\section{PATIENT'S CONSENT:}

The written informed consent has been obtained from the guardian of the patient.

\section{CONFLICT OF INTEREST:}

The authors declared no conflict of interest.

\section{AUTHORS' CONTRIBUTION:}

SG, SVS: Contributed to prosthesis design, fabrication and manuscript preparation.

NS: Contributed to manuscript preparation.

DA, PC: Contributed to literature review.

\section{REFERENCES}

1. Pruthi G, Jain V, Sikka S. A novel method of retention of an orbital prosthesis in a case with continuous maxillary and orbital defect. J Indian Prosthodont Soc 2010; 10(2):132-6.

2. Veerareddy C, Nair KC, Reddy GR. Simplified technique for orbital prosthesis fabrication: A clinical report. J Prosthodont 2012; 21(7):561-8. doi: 10.1111/j.1532849X.2012.00869.x.

3. Guttal SS, Alva B, Nadiger RK. Use of a stud attachment to retain a silicone orbital prosthesis: A clinical report. J Prosthodont 2012; 21(4):317-21. doi: 10.1111/j.1532849X.2011.00812.x.
4. Kiat-amnuay S, Gettleman L, Khan Z, Goldsmith LJ. Effect of adhesive retention on maxillofacial prostheses. Part I: Skin dressings and solvent removers. J Prosthet Dent 2000; 84(3):335-40. doi: 10.1067/mpr.2000.109507.

5. Toljanic JA, Eckert SE, Roumanas E, Beumer J, Huryn JM, Zlotolow IM, et al. Osseointegrated craniofacial implants in the rehabilitation of orbital defects: An update of a retrospective experience in the United States. J Prosthet Dent 2005; 94(2):177-82. doi: 10.1016/j.prosdent. 2005. 04.016 .

6. Arcuri MR, LaVelle WE, Fyler E, Jons R. Prosthetic complications of extraoral implants. J Prosthet Dent 1993; 69(3):289-92. doi: 10.1016/0022-3913(93)90108-z.

7. Tummawanit S, Shrestha B, Thaworanunta S, Srithavaj T. Late effects of orbital enucleation and radiation on maxillofacial prosthetic rehabilitation: A clinical report. J Prosthet Dent 2013; 109(5):291-5. doi: 10.1016/S00223913(13)60303-0.

8. Quaranta-Leoni FM. Treatment of the anophthalmic socket. Curr Opin Ophthalmol 2008; 19(5):422-7. doi: 10.1097/ ICU.0b013e32830b1551.

9. Li D, Jie Y, Liu H, Liu J, Zhu Z, Mao C. Reconstruction of anophthalmic orbits and contracted eye sockets with microvascular radial forearm free flaps. Ophthal Plast Reconstr Surg 2008; 24(2):94-7. doi: 10.1097/IOP. 0b013e318166dad1.

10. Guttal SS, Patil NP, Nadiger RK, Rachana KB, Dharnendra, Basutkar N. Use of acrylic resin base as an aid in retaining silicone orbital prosthesis. J Indian Prosthodont Soc 2008; 8:112-5. 